La arquitectura que ha usado con columnas toscanas apoyadas directamente sobre un entablamento sobre el que arrancan bóvedas de arista separadas por arcos fajones y con un luneto semicircular ciego, sin ventana que da al exterior, parece reflejar algunos de los estudios del tratadista flamenco en sus libros sobre perspectiva, especialmente el último y más famoso, Perspective publicado en La Haya y Leyden en 1604-1605 ${ }^{29}$.

JOSÉ MARÍA QUESADA VARELA

\title{
OTROS OBJETOS ITALIANOS REPRESENTATIVOS DEL MECENAZGO DE LOS MEJORADA EN EL MONASTERIO DE GUADALUPE
}

Una muestra de la actividad de mecenazgo religioso de la nobleza inserta en el espíritu de la época, está bien representada por las donaciones a fundaciones y monasterios importantes. Don Pedro Fernandez del Campo obtuvo el título de marqués de Mejorada en 1673. Desde el acomodo de su cargo, como consejero de Felipe IV en la Junta de Guerra y en el Consejo de Indias y más tarde secretario del Despacho Universal, mostró un espiritu refinado, llegando a poseer una abundante colección de pintura, escultura, tapicerías y muebles suntuosos. En la primera se advierte un equilibrio entre obras italianas y flamencas. Respecto a la escultura, en cambio, muestra su preferencia por las obras de arte italianas, contandose más de doce figuras napolitanas. Y lo mismo sucede con su mobiliario entre el que se contaban importantes piezas representativas del lujo de la época como eran esencialmente los escritorios, los espejos, los bufetes, e incluso un biombo de laca china ${ }^{1}$.

En el Monasterio de Guadalupe se conservan dos escritorios y seis espejos de cristal de roca.Todos ellos figuran, como regalos de los marqueses de Mejorada, en los documentos conservados en el Archivo Histórico Nacional, documentación ya constatada por Mélida en $1914^{2}$. Villacampa en 1924 y el padre Germán Rubio en 1926, al comentar pormenorizadamente la Sacristía y el Camarín del monasterio, comenzada aquella en 1638 y este entre 1687-96 van refiriendo como gran parte de las obras y elementos decorativos fueron sufragados por la nobleza ${ }^{3}$, las donaciones de los duques de Bejar el trono de plata de la Virgen, regalo del marqués de Monesterio, la araña de cristal de roca donada por el duque del Infantado, que primero estuvo en la capilla mayor y hoy en el camarín, para cuya obra la duquesa de Aveiro ofreció 6.000 ducados en 1687 y citan también los escritorios como donados por los marqueses de Mejorada en $1689^{4}$, noticia recogida por Cavestany en $1930^{5}$.

La relación del segundo marqués de Mejorada, don Pedro Cayetano Fernandez del Campo, con Guadalupe debió ser intensa, pues figuran entre los registros los «seis espejos regalo

29 Vredeman De Vries, Jan: Perspective, Leiden, 1604-1605. En este artículo he usado la edición a cargo de Adolf. K. Placzek, Nueva York: Dover Publications, 1968. Las láminas más cercanas a la de nuestro cuadro serían las n. ${ }^{\text {s. }} 22,27$ y 44 , en las que aparecen los mismos elementos arquitectónicos y guardando una semejanza notable.

\footnotetext{
1 A.H.P. Madrid Protocolo 10.066, publicado por J.L.Barrio Moya: «Las colecciones de pintura y escultura del primer marqués de Mejorada», Hidalguía, año 30, nov-dic. 1982 n. 175.

2 Catálogo Monumental de España. Provincia de Cáceres. Madrid 1914-16, vol.II p. 186.

3 Carlos de Villacampa: Grandezas de Guadalupe. Madrid 1924, pp. 437-438.

4 Historia de Nuestra Señora de Guadalupe. Barcelona 1926, pp. 159; 167-68 y 461.

5 «Industrias artísticas. El coral y su talla en España». Arte Español. 1930-31, pp. 156-162.
} 
del marqués de Mejorada al Monasterio» tasados en 40.000 ducados y donados en $1687^{6}$, pero no los escritorios, que sí aparecen, sin embargo en la tasación de los bienes de su padre, que tiene lugar tras su muerte en 1680 , como «dos escriptorios de piedra y pasta embutidos y guarnecidos de coral con ojas de plata» tasados por el ebanista Juan Fernandez de la Fuente el 27 de noviembre ${ }^{7}$. Los dos escritorios pues, fueron enviados a Guadalupe por el segundo marqués en 1689. La donación no fue absolutamente desinteresada, pues entre la documentación del Archivo Histórico Nacional. consta una orden de Felipe V dada en Madrid a 11 de junio de 1721, de dar sepultura al corazón del marqués de Mejorada en el altar mayor, atendiendo a la petición de este, a lo que se negó la comunidad por ser sepultura de reyes, aprobándose hacerlo bajo la primera grada de la entrada de la iglesia ${ }^{8}$.

Los seis espejos (Fig. 22) son una magnífica representación del refinamiento veneciano de la segunda mitad del siglo XVII. Colocados en los ochavos del Camarín de las Reliquias, se dispusieron apaisadamente con el copete en los lados largos y son exactos a los que se conservan en el Museo Poldi.Pezzoli de Milán y a los de la sacristía del Monasterio de El Escorial, entre otros.

Los escritorios (Fig. 23), en cambio, son excelentes representantes del gusto napolitano de la misma época. Su ornamentación principal consiste en placas de piedras duras, decorando los frentes de los cajones y la portada central, columnas salomónicas con coral y restos de planchas de bronce o plata dorada encuadrando aquéllas. Claramente fabricados para exhibirse por parejas, como era costumbre en Nápoles y España en la segunda mitad del siglo XVII, ambos ejemplares son prácticamente iguales. En el entablamento y entre las columnas se adornaban con placas de lapislázuli, perdidas también en su mayor parte. La portada central representa a Orfeo sentado tocando entre árboles en un jardín cerrado por una tapia con dos perros sentados a su lado. El resto de las placas, tanto las de las gavetas, como los tímpanos y las que ornan los pedestales ostentan composiciones de un solo animal de especies variadas, camellos, rinocerontes, renos, caballos, perros, osos, excepto una pequeña bajo el frontispicio con un perro atacado por dos jabalíes.

Conocemos actualmente al menos tres escritorios más con placas exactamente iguales. Una pareja que conserva todos los adornos de plata se hallan en el Château de Beloeil, propiedad de los descendientes del príncipe de Ligne, Claudio Lamoral, quién fue virrey de Sicilia entre $1670-1674^{\circ}$, procedencia ya advertida por Gonzalez Palacios, quien considera las placas florentinas ${ }^{10}$. El tercero, hoy en la colección March de Mallorca ${ }^{11}$, es muy distinto en su arquitectura, pero se adorna con idénticas placas ${ }^{12}$.

6 Libro de las actas capitulares de esta Santa y Real casa de Guadalupe començo a servir en el mes de Febrero de 1671 siendo prior a RNP Frey Fernando del Arroyo 3. ${ }^{a}$ vez y su vicario el p. Frey Hieronimo de Granada. A.H.N. Códice 103-b, fol. 103.

7 Véase nota 1.

8 Códice 103-B fol. 205 vto. Para este tema véase el artículo de Margarita Estella en este mismo número «El mecenazgo de los marqueses de Mejorada en la iglesia y capilla de Sevilla».

9 G. Coniglio, Il Viceregno di Napoli nel secolo XVII. Roma 1955,

10 A.Gonzalez Palacios: «Un adornamento vicerreale a Napoli» Civiltá del Seicento Napoletano. 1978 nota 62, ilustrado en Ria Fabbri. Meubles d'apparat des Pays-Bas meridionaux: XVIe-XVIIle siècle. Bruselas, 1989 , p. 34. p. 261

Aparece fotografiado en el Palau March en Casas Señoriales de España. G G Barcelona, 1992,

12 Conocido como «Cabinet d'Orphée» o «del rey de Suecia Carlos X», y considerado mueble italiano en la colección de la condesa Louise Gyldenstope, fue vendido en Paris, Galerie Georges Petit 14-15 mayo 1923, 

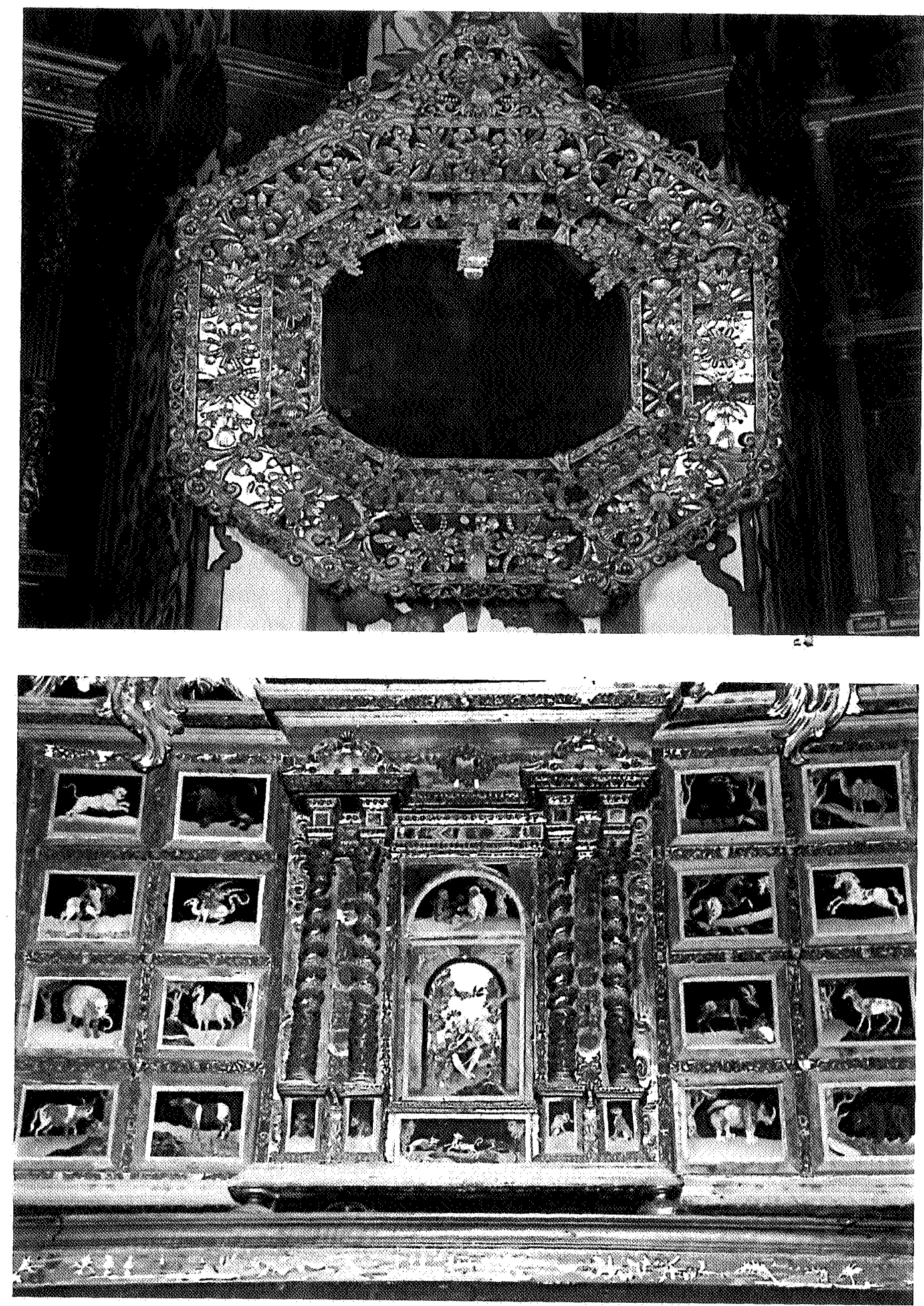

Figura 22. Espejo veneciano. Segunda mitad s. XVII. Monasterio de Guadalupe (Cáceres).

Figura 23. Escritorio siciliano. Hacia 1650. Monasterio de Guadalupe (Cáceres). 
Así como los tres últimos llevan un escudo, que refleja el ser pieza de encargo, los nuestros llevan una pequeña cartela de metal dorado rodeada de coral. La comparación sobre todo con los de la colección belga permite conocer exactamente como eran las chapas que ornaban no solo los frentes, sino también la caja del mueble, prácticamente desaparecidas en los de Guadalupe ${ }^{13}$.

La ornamentación en coral y plata dorada o bronce, tuvo su principal centro de producción seicentista en Palermo, de cuyos talleres proceden la mayoría de las piezas conservadas desde la década de los cuarenta ${ }^{14}$, fecha que parece coincidir estilísticamente con la de los dos escritorios, de proporciones regulares y distribución sencilla, muy en consonancia con los que se realizan en Napoles en ébano y marfil. En los talleres granducales por esos mismos años se decoran los escritorios con placas de mármoles y piedras duras. El liderazgo florentino es reconocido en toda Europa, pero la producción se extiende a otros talleres, no necesariamente de la propia Galería, incluso a otras ciudades, como Nápoles, adonde llegaron los diseños de Ligozzi y otros, combinándose con una decoración propia siciliana como es el coral. No son muy habituales en la manufactura de los artistas granducales estas imágenes de animales silueteados sobre un fondo de paragone, prefiriendose los pájaros y las flores, pero bien pudieron hacerse las placas en Florencia y llevarse en conjunto para montar en los frentes de los muebles, o haberse realizado en Nápoles por artistas toscanos allí establecidos como fue, entre otros, Domenico Montini, el maestro senés que realizó el tabernáculo de Felipe III ya que no es raro encontrar en inventarios españoles escritorios decorados «con payses en piedra de Nápoles» ${ }^{15}$.

María PAZ AgUiló

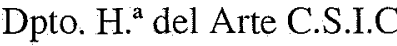

\section{LOS RELIEVES DE BACANALES QUE DECORABAN EL ALCÁZAR *}

Ya teníamos noticias por Bellori, de los regalos que el Cardenal Barberini hizo llegar a la corte española, y sobre los que ahora, podemos hacer alguna precisión. Se señala en la edición moderna de la obra de Bellori, que el biógrafo equivoca el relieve que acabó en el Alcázar madrileño, ya que la obra citada como copia de Tomaso Fedele en pórfido, siguiendo el

lote 204 , de donde parece pasó a la colección española. Las placas están montadas en una caja mucho más grande sobre pies con soportes antropomórficos, basados en I Cinque Libri di Architectura de Montano editados en. Roma en 1684 que inspiraron el grabado de Pierre Gole «Les cabinets de la Guerre et de la Paix», y atribuido en su arquitectura, a René Chauveau, ebanista casado con la hija de Domenico Cucci, artista florentino director de la Manufactura de los Gobelinos, cfr. C.Demetrescu «Domenico Cucci, le plus baroque des ebenistes de Louis XIV», L'Objet d'Art. n. ${ }^{\circ} 306$. Octubre, 1996, pp. 58-75.

${ }_{13}$ Por su colocación inaccesible en el pequeño reservado del Joyel no se ha podido constatar si los fragmentos que aún consevan son de plata dorada o de bronce.

14 Fernando Martín en el catálogo de plata del Convento de Santa Isabel, rastrea el origen palermitano de piezas allí existentes adelantando su fecha hasta 1645-1647, año en que don Juan de Austria envía a Felipe IV el cuadro de Ribera. Real Fundación del Convento de Santa Isabel de Madrid, 1990, p. 155 y ss.

15 Barrio Moya: «La librería de la dama madrileña Doña María Josefa de Cuéllar y Losa (1704), Anales del Instituto de Estudios Madrileños, 1996, p. 415.

\footnotetext{
* Mi agradecimiento a Margarita Estella Marcos, por su ayuda.
} 